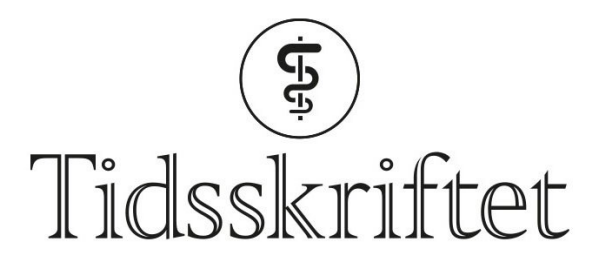

DEN NORSKE LEGEFORENING

\title{
The Zika outbreak in Brazil: An unequal burden
}

GLOBAL HELSE

\section{SUSANNE SKRÅNING}

Susanne Skråning (born 1994), MPhil student at the Department of Community Medicine and Global Health, Institute of Health and Society, University of Oslo. BSc in Anthropology from University College London (UCL) in 2016.

The author has completed the ICMJE form and reports no conflicts of interest.

\section{BENEDIKTE V. LINDSKOG}

E-mail: b.v.lindskog@medisin.uio.no

Benedikte V. Lindskog (born 1969), PhD in Social Anthropology (University of Oslo, 2011). Researcher since 2011 and is currently a research associate at the Department of Community Medicine and Global Health, Institute of Health and Society, University of Oslo.

The author has completed the ICMJE form and reports no conflicts of interest.

The Zika outbreak in Brazil in 2015-16 had detrimental medical, financial and social consequences for many children and their families. This article seeks to explore the current challenges that they are facing, and how these can be met. A 'One Health' perspective can help to address these complex issues.

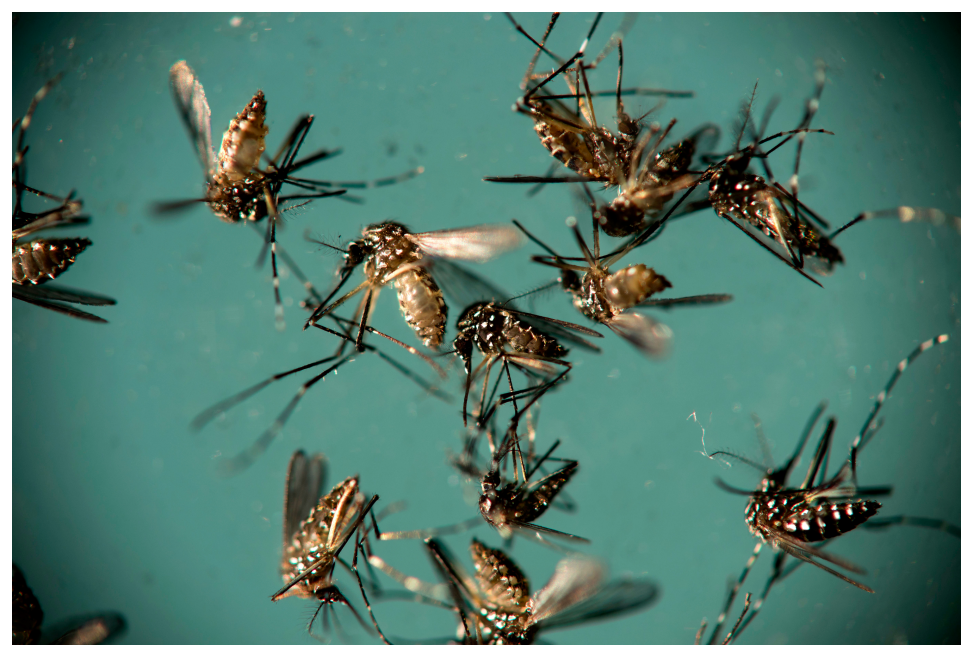

Aedes aegypti mosquitoes. Photo: AP/Felipe Dana/NTB scanpix

The burden of the Zika outbreak in the tropical Americas from 2015-16 crucially encompasses challenges related to gender inequality, poverty, social stigma, as well as women's actual and legal access to reproductive and maternal care, including safe abortions. Currently in Brazil, many of the affected women and their families are experiencing additional challenges in their everyday lives due to poverty, as well as systemic 
and structural issues related to healthcare delivery and social security. It is necessary to explore and understand these issues in order to provide proper care and support to victims of the Zika epidemic, and to ensure preparedness for dealing with both present and future consequences.

In this article, we provide a brief overview of the recent history of the Zika outbreak in Brazil with a particular focus on women and their children born with microcephaly and other neurological complications. We seek to highlight some of the social, economic and systemic consequences the outbreak has had for the affected families, based on empirical data and interviews from a qualitative study conducted in the most affected region of Brazil during the summer of 2017 (these data constitute part of the qualitative data collected during fieldwork as part of Skråning's research for her Master's thesis. The thesis will be finalised in Spring 2018 and is hence unpublished material.).

The Zika virus is vector-borne; therefore, we suggest that a 'One Health' perspective is appropriate when discussing the epidemic, as it provides a promising step towards a holistic alignment of causal interactions between the health of humans, animals and the environment. As described by the WHO, 'One Health' is "an approach to designing and implementing programmes, policies, legislation and research in which multiple sectors communicate and work together to achieve better public health outcomes" (1).

In a world of climate change and increased mobility of people and objects, there is an everpresent potential for global circulation of zoonotic and vector-borne diseases. Therefore, the governance of outbreaks and epidemics requires approaches that do not deal with human health in isolation (2), but rather see humans, animals, pathogens and their local environments as always mutually enmeshed. Such an approach allows for, as highlighted by the Zika outbreak, an understanding of not only the causal pathways between humananimal ecologies, but importantly also brings to light socio-political issues of poverty, inequity and inequality.

\section{The beginning of an epidemic}

The mosquito-borne Zika virus (ZIKV) was first discovered in rhesus monkeys in Kampala, Uganda, in 1947 (3). The Zika virus is carried by mosquitoes in the Aedes family, predominantly the Aedes aegypti. In addition to mosquito transmission, the virus can be transmitted through vaginal, anal and oral sex (4). In most cases, ZIKV infections do not cause any symptoms (5). However, the infection may lead to Zika fever, which results in mild, flu-like symptoms, and sometimes a red rash. Hence, the symptoms can be mistaken for those of Chikungunya and Dengue fever, which are both transmitted through the same vector (3).

A Zika diagnosis is obtained through laboratory testing of blood, urine or other bodily fluids. The WHO recommends two testing strategies for confirming Zika virus infection: nucleic acid testing for Zika RNA and serological testing for IgM antibodies against Zika (6). Currently, there is no treatment available for the virus, besides symptomatic treatment. Although it is believed that the Zika virus entered Brazil in 2014, the first dozen cases were identified in the Northeast region by May 2015, which later became the epicentre of the 2015-16 Zika epidemic in South America (7).

\section{The discovery}

It would become evident that the Zika virus caused far more serious conditions than Zika fever, particularly for women who were infected during pregnancy (8). During fieldwork for her Master's thesis in the Northeast region of Brazil, from June-August 2017, Skråning visited a newly-opened treatment and research centre for Zika victims run by Dr Adriana Melo and her team in the city of Campina Grande, Paraíba: Instituto De Pesquisa Professor Joaquim Amorim Neto (IPESQ). Dr Melo, a physician specialising in high-risk pregnancies, was the first to discover the link between the Zika virus and congenital anomalies. 
While performing an ultrasound on one of her patients she found that the foetus had microcephaly; that is, atypical development of the brain which results in a smaller head. However, Dr Melo was surprised to find both genetic and infectious causes in the foetus; she had never seen both at the same time throughout her 20 years of experience with ultrasounds and congenital malformations.

Two weeks after the first ultrasound, Dr Melo performed a second: the head of the foetus had not grown. During the same period, Dr Melo had seen another woman whose sonogram showed similar, but more severe symptoms; she sent both samples of amniotic fluid to a research institution in Rio de Janeiro. A few days later the results came back; traces of the Zika virus were found in both samples, which established an association between Zika infection during pregnancy and severe, congenital anomalies.

\section{The response}

Dr Melo explained that it would take nearly two months from this discovery for the information to be made available to the public. In November 2015, the virus was officially linked to an increase in cases of microcephaly and other central nervous system malformations, henceforth referred to as Congenital Zika Syndrome (CZS) (9). In addition, the virus was associated with an increase in cases of Guillain-Barré syndrome. In response, the Brazilian government declared a national health emergency and set up a system for notification of all suspected cases of CZS and Guillain-Barré (8). In addition, the government created an action plan to prevent the spreading of Zika through the Aedes aegypti mosquito, which focused on three main areas of intervention; mobilisation of the population to fight the mosquito, providing assistance to the population, and education, technological development and research.

These severe outcomes of the Zika epidemic eventually led to the declaration of a Public Health Emergency of International Concern by the WHO on the $1^{\text {st }}$ of February, 2016 (8). According to the latest situational report by the WHO from February 2017, 2366 cases of congenital Zika syndrome in Brazil are associated with Zika infection during pregnancy (10). However, most of the registered cases of congenital Zika syndrome in Brazil occurred in late 2015, with a steady decrease until mid-2016 (11). There was a slight increase in Zikaassociated congenital anomalies in the latter half of 2016, however in 2017 there have been very few registered cases, and only a slight increase in Zika infections (11). Due to this decline, the Public Health Emergency of International Concern over Zika ended in November 2016 (8). The Brazilian national health emergency came to an end on the $11^{\text {th }}$ of May, 2017.

\section{Where are we now?}

\section{FINANCIAL CONSTRAINTS AND ACCESS TO SPECIALISED HEALTHCARE}

Although the number of new cases of congenital Zika syndrome has gone down, the 2015-16 Zika epidemic has had, and continues to have, a major impact on the affected children, their families and communities. The Brazilian health system is divided into a public and private sector; around 70 \% of the population rely solely, or mainly on the Sistema Único de Saúde (SUS), which is publicly funded (12, p. 6). All of the 51 mothers Skråning interviewed during her fieldwork relied on the public system; at the treatment centre run by Dr Melo in Campina Grande, only two out of 120 mothers had private health insurance.

The national health system in Brazil is highly decentralised; access to specialised care and diagnostic services is restricted for those who rely on the public system, due to financial constraints of the SUS and weak referral systems for facilities that fall outside of the municipal health services (12, p. 6). Skråning met the majority of the mothers who were affected by the Zika outbreaks through Caravana do Coração, which is part of a local NGO based in Pernambuco and Paraíba that offers much-needed primary and specialised paediatric care in poor, rural areas over a two-week period annually. However, children with 
microcephaly require daily access to personalised medical care, as well as physiotherapy. According to Dr Melo, most of the families affected by the Zika epidemic rely on the public system, and some of the children may have to wait up to one year for referrals.

The Northeast of Brazil, which was hardest hit by the outbreak, is also the poorest region in the country (8). Indeed, the vast majority of mothers to children with congenital Zika syndrome whom Skråning interviewed during her fieldwork were facing financial constraints, and many were living in over-crowded slum areas, referred to as periferias. The main vector of the virus, the Aedes aegypti mosquito, breeds in clear, stagnant water; thus, poor areas that lack sufficient sanitation systems, piped water lines and infrastructure for waste management form ideal breeding grounds for the mosquitoes (3).

According to a recent report by Human Rights Watch, "more than one-third of Brazil's 208 million people do not have access to a continuous water supply [...]" (8, p. 23). Each house therefore stores water in a tank on the roof, or in buckets; if these are not covered, they form perfect habitats for breeding mosquitoes. In this sense, human activity has an influence on disease burden and incidence. The complexity of the situation in Brazil thus illustrates the need for a multidisciplinary approach that links the health of people to the well-being of the environment and animals. A One Health perspective provides a promising conceptual framework and point of departure for addressing these linkages.

\section{ACCESS TO TREATMENT IN A DECENTRALISED SYSTEM}

Little is known about how the various impairments associated with congenital Zika syndrome will affect the future development of the children. Yet, what is clear is that children with life-long Zika-associated conditions rely on continuous access to rehabilitation treatment, such as physical, occupational and speech therapy (13). Following the Zika epidemic, the Brazilian government has invested in 63 new specialised public rehabilitation centres for people with disabilities (8).

However, many of the mothers that Skråning met in the field came from smaller municipalities that did not offer such services, resulting in long journeys of $4-6$ hours to urban centres for treatment sessions. A 17-year-old mother, whose son with microcephaly was one year and three months, explained that she had to leave her town at in the middle of the night to make it to the morning appointments in a larger city. She made this journey four times a week; twice to the governmental hospital in the city, and twice to the clinic run by Dr Melo. Due to the long travel distances, some mothers ended up spending the night at the clinic with their children. A mother of two children with autism and microcephaly explained:

My life has changed a lot. I am very tired. [...] This is my life now. Therapy for one, then the other. It is just this.

Due to the considerable amount of time that the weekly treatment sessions require, none of the mothers were able to work; this resulted in further financial constraints on the families.

\section{SOCIAL SECURITY}

Bolsa Família is a conditional cash transfer programme for poor families that earn less than R\$140.0o (NOK 370) per person, per month (12, p. 14). Many of the mothers that Skråning met during her fieldwork received, or had previously received this support. In 2016, all children with Zika-associated conditions became entitled to a federal financial benefit for people with disabilities of R $\$ 937$ (NOK 2530) monthly (8). Some were struggling to access this benefit, particularly if their husbands were working. The families who started receiving this benefit subsequently lost their support from Bolsa Família, as they could not receive two benefits at once. The federal financial benefit for children with congenital Zika syndrome is only provided for three years; in three instances, mothers told Skråning that they had asked social workers at the hospital why they did not receive support for longer. All three received the same answer; according to studies, their children would not survive 
beyond the age of three.

The majority of mothers who received the disability benefit said that the amount was too low, and that it barely covered monthly medical expenses. What became evident from the conversations with mothers affected by the Zika epidemic was that having a child with severe disabilities caused additional economic constraints for the already disenfranchised families, with the state support barely meeting their social and medical needs.

\section{An interdisciplinary and multilevel approach}

The Zika outbreak underscores the importance of seeing the environment and animal behaviour as inseparable from human activity. The spread of the Zika virus relied on a range of unfortunate circumstances, of which poor physical living conditions coupled with lack of access to clean, running water and sanitation was crucial.

As has become apparent in the aftermath of the Zika outbreak in Brazil, people already living in poverty were clearly affected the most, highlighting the escalating vulnerability and precariousness poor people face in societies with severe socio-economic inequalities. Hence, poor sanitary conditions, lack of a national vector control programme and drought that had spanned over several years all contributed to excellent conditions for mosquitoes and the diseases they carry, including Zika. A comprehensive framework such as a One Health perspective that embraces multilevel, systemic, as well as contextual approaches is essential to understand and tackle the consequences of the Zika epidemic.

In order to meet global health challenges like the Zika outbreak, interdisciplinary collaborations are vital to the development of knowledge and to establish scholarly synergies from which concrete strategies, policies and interventions can emerge. As the anthropologist Wolf has noted: “...it is important for both - the natural and the social sciences - to recognize that the global embeddedness of infectious disease ecologies is a product of biological and social relations" (2, p. 6). Thus, to fully grasp, and to act on, the consequences of events like the 2015-16 Zika outbreak, we need to acknowledge the social, political and economic determinants in the One Health triad of humans, animals and the environment.

\section{REFERENCES:}

1. World Health Organisation. One Health. 2017. http://www.who.int/features/qa/one-health/en/ (13.10.2017).

2. Wolf M. Is there really such a thing as “one health"? Thinking about a more than human world from the perspective of cultural anthropology. Soc Sci Med 2015; 129: 5 - 11. [PubMed][CrossRef]

3. Singer M. The spread of Zika and the potential for global arbovirus syndemics. Glob Public Health 2017; 12: 1 - 18. [PubMed][CrossRef]

4. Brooks RB, Carlos MP, Myers RA et al. Likely Sexual Transmission of Zika Virus from a Man with No Symptoms of Infection - Maryland, 2016. MMWR Morb Mortal Wkly Rep 2016; 65: 915 - 6. [PubMed][CrossRef]

5. Carvalho BR, Taitson PF, Brandão KS et al. Reproductive planning in times of Zika: getting pregnant or delaying plans? The opinion of the Brazilian Society of Assisted Reproduction Committee - a basis for a bioethical discussion. JBRA Assist Reprod 2016; 20:159 - 64. [PubMed][CrossRef]

6. World Health Organisation. Laboratory testing for Zika virus infection. 23 March 2016. World Health Organisation, 2016.

http://apps.who.int/iris/bitstream/10665/204671/1/WHO_ZIKV_LAB_16.1_eng.pdf?ua=1 (20.10.2017).

7. Weaver SC, Costa F, Garcia-Blanco MA et al. Zika virus: History, emergence, biology, and prospects for control. Antiviral Res 2016; 130: 69-8o. [PubMed][CrossRef]

8. Watch HR. Neglected and Unprotected: The Impact of the Zika Outbreak on Women and Girls in 
Northeastern Brazil. Human Rights Watch, 2017.

https://www.hrw.org/report/2017/07/12/neglected-and-unprotected/impact-zika-outbreak-women-andgirls-northeastern-brazil (15.8.2017).

9. Moura da Silva AA, Ganz JS, Sousa PD et al. Early Growth and Neurologic Outcomes of Infants with Probable Congenital Zika Virus Syndrome. Emerg Infect Dis 2016; 22: 1953 - 6. [PubMed][CrossRef]

10. World Health Organisation. Situation report: Zika virus, Microcephaly and Guillain-Barré. 2 February 2017. World Health Organisation, 2017.

http://apps.who.int/iris/bitstream/10665/254507/1/zikasitrep2Feb17-eng.pdf?ua=1 (15.8.2017).

11. PAHO. Zika-epidemiological report: Brazil. 29 June 2017. World Health Organisation, 2017.

http://www2.paho.org/hq/index.php?optioncom_docman\&task-

doc_view\&gid=35221\&Itemid=270\&langen (15.8.2017).

12. Couttolenc B, Dmytraczenko T. Brazil's Primary Health Care Strategy. Washington DC: The World Bank; 2013.

http://documents.worldbank.org/curated/en/881491468020373837/pdf/749570NWPoBRAZooBox374316 BooPUBLICo.pdf(20.10.2017).

13. Cicuto Ferreira Rocha NA, de Campos AC, Cicuto Ferreira Rocha F et al. Microcephaly and Zika virus: Neuroradiological aspects, clinical findings and a proposed framework for early evaluation of child development. Infant Behav Dev 2017; 49: 70 - 82. [PubMed][CrossRef]

Published: 28 November 2017. Tidsskr Nor Legeforen. DOI: 10.4045/tidsskr.17.0655

Received 1.8.2017, first revision submitted 15.10.2017, accepted 20.10.2017.

(C) The Journal of the Norwegian Medical Association 2020. Downloaded from tidsskriftet.no 